\title{
El imperativo romántico. El primer romanticismo alemán, Frederick C. Beiser
}

Moisés Moreno Medellín

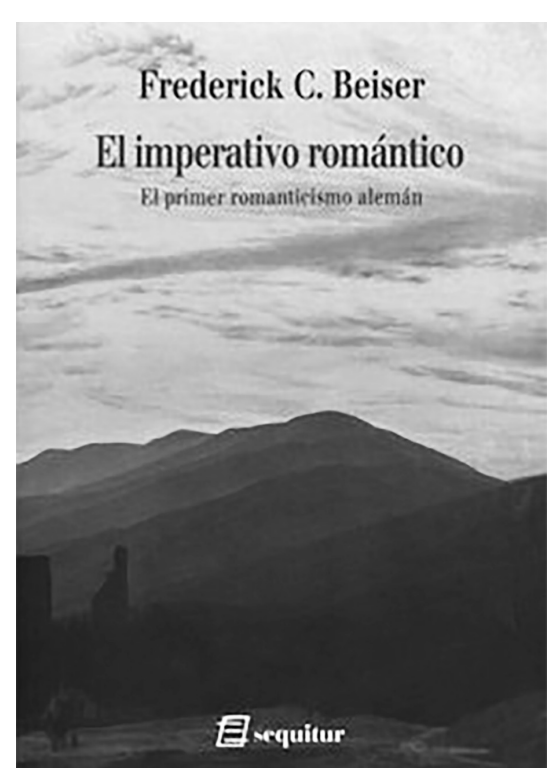

Beiser, Frederick C. El imperativo romántico. El primer romanticismo alemán. Madrid: Sequitur, 2018. 320 pp.
Frederick C. Beiser, autor de El imperativo romántico (2003), es doctor en filosofía por el Wolfson College de Oxford, grado que obtuvo al presentar la tesis intitulada "The Spirit of the Phenomenology: Hegel's Resurrection of Metaphysics in the Phänomenologie des Geistes”, dirigida por Charles Taylor. Ha sido merecedor de las afamadas becas Thyssen y Humboldt, con las cuales pudo realizar dos estancias de investigación en la Free University of Berlin. A lo largo de su carrera se ha distinguido por sus contribuciones a la filosofía con estudios de gran calidad y profundidad sobre el pensamiento germano; en específico del idealismo y el romanticismo alemán, sobre autores 
como Kant, Schlegel y Hegel. Es autor de libros como: The Fate of Reason: German Philosophy from Kant to Fichte (1987) el cual fue galardonado con el importante Thomas J. Wilson Prize; Enlightenment, Revolution and Romanticism: The Genesis of Modern German Political Thought, 1790-1800 (1992), German Idealism: The Struggle against Subjectivism, 1871-1800 y Hegel (2005). Ha trabajado con grandes profesores del mundo angloparlante, entre los que destacan: Terry Pinkard, Robert Pippin y Karl Ameriks.

En El imperativo romántico, el profesor Beiser nos presenta diez ensayos (a manera de capítulos) donde el objetivo principal es proponer una lectura innovadora del romanticismo alemán; alejada de la influencia del pensamiento proveniente del idealismo alemán. Lo anterior lo muestra al plantear como tesis fundamental que la estética del primer romanticismo (Frühromantik) es una formulación filosófica con fines metafísicos, epistemológicos, éticos, políticos e incluso religiosos. Esto trasciende a la visión tradicional estética del romanticismo, que se limita a estudiar las representaciones artísticas. Nuestro autor man- tiene un diálogo crítico con las obras de intelectuales postmodernistas tales como Ernst Behler y Lacoue-Labarthe; proyectando una relación entre la ilustración alemana (Aufklärung) y la Frühromantik, argumentada a través de los métodos hermenéutico e histórico; así pretende reconstruir las categorías románticas desde el seno mismo de este pensamiento.

Para Beiser la importancia de la Frühromantik estriba en que los jóvenes filósofos románticos de este periodo llevaron a cabo una clara ruptura con el pensamiento cartesiano, la cual se observa, principalmente, en su rechazo a la duda como método filosófico y al hecho de no aceptar que la razón provea a los hombres, por sí misma, de conocimiento certero y verdadero. Otro elemento fundamental que resalta la importancia de este momento histórico es la resistencia a la tesis ilustrada de una razón histórica como leitmotiv del desarrollo de la vida de los hombres.

El interés de nuestro autor por el romanticismo surge del olvido que sufrió esta corriente de pensamiento después de la Segunda Guerra Mundial, debido a la desacreditación de la 
que fue objeto por parte de la filosofía marxista, el fascismo y los diferentes movimientos literarios de la primera mitad del siglo xx. Beiser busca y encuentra en la Frühromantik una metafísica que propone un concepto de naturaleza, un equilibrio con la razón ilustrada; asimismo, propone al amor y a la individualidad como categorías reaccionarias al formalismo kantiano y a la filosofía de Fichte. Sumado a lo anterior, nuestro autor detecta en la estética de la Frühromantik una forma eficiente de debilitar los estándares artísticos del clasicismo, ya que en esta época se produjeron nuevas formas de crítica artística, que respetaban tanto el contexto como la individualidad de la obra misma. En el plano político, los románticos presentaron una fuerte crítica al contractualismo moderno, tratando de revivir la polis griega.

En el primer capítulo, "El significado de poesía romántica”, nuestro autor nos dice, junto con Schlegel, que la poesía romántica (romantische Poesie) designa cualquier uso literario del lenguaje que tenga como finalidad la belleza, sin importar que dicho uso sea en prosa o en verso. Asimismo, nos explica que Schlegel distingue entre la poesía y otras artes como la música y la escultura, según los medios con que se desarrollan las artes; así, la música se desenvuelve por el movimiento, la escultura, por el cuerpo y la poesía, a través del lenguaje. Por último, nos habla sobre la concepción artística de Schlegel, la cual propone a la poesía como una sofisticada totalidad autoconsciente, que dota de libertad e igualdad a todos los hombres, cumpliendo así con el ideal de la época moderna.

En el siguiente capítulo, intitulado "El primer romanticismo alemán. Una caracterización”, nuestro autor nos refiere cómo, para el romanticismo, el aspecto ético y el político tienen prioridad sobre el aspecto estético, en tanto que los ideales estéticos de éste fueron originados por los éticos y políticos propuestos por los mismos románticos. Esto objetaría las tesis que consideran al romanticismo como una corriente de pensamiento apolítica, misma que, intenta abstraerse de su entorno social. Beiser apoya la tesis contraria, nos explica que toda la literatura romántica se sustenta en el ideal ético y político de la autorrealización del individuo (Bildung), cuyo objetivo era la creación de una unidad 
del individuo consigo mismo, con los demás y la naturaleza; como era la pretensión en la Antigüedad.

En el tercer apartado, "El primer romanticismo y la Aufklärung", Beiser explica que el romanticismo es un pensamiento que rompe con la $A u$ fklärung; en lugar de aceptar la razón como máxima autoridad, le otorgaba este puesto a los sentimientos del arte. Los románticos no aceptaban el ideal ilustrado de la comunidad, en cambio, proponían al individuo como aquel que debía sacrificarse por el bien de la comunidad. Nuestro autor afirma que el romanticismo es una ideología principalmente conservadora, no acepta las propuestas liberales de la Aufklärung tales como: el Estado laico, la pluralidad religiosa y el liberalismo.

En el capítulo "La Frühromantik y la tradición platónica”, Beiser afirma que, a pesar de todas las diferencias que tradicionalmente podemos encontrar entre el romanticismo y la Aufklärung, ambas compartían la Bildung como ideal fundamental para educar al pueblo, con ella, es posible alcanzar los objetivos de la razón en la vida pública. Con la expresión "vino nuevo en botellas viejas", escribe que la mayoría de los Romantiker no aceptaban la razón como instrumento último de conocimiento, esto entendiendo a la razón en el mismo sentido en que lo hacía la lógica de Port Royal. Lo anterior debido a que los Romantiker sostienen que la razón falla en su empresa de conocimiento, pues es sumamente limitada para captar el infinito; mientras que los sentimientos e intuiciones del artista pueden acceder a lo que se oculta a los conceptos de la razón. La propuesta romántica adquiere un carácter suprarracional que soluciona las limitantes de la razón, captadas y presentadas sólo a través del arte. Los Romantiker conciben al universo como una unidad orgánica, lo cual es concebible sólo si dicha unidad es vista como una obra de arte.

El quinto segmento, de nombre "La soberanía del arte", plantea que los Romantiker proponen al arte como metafísica, pues es lo único que puede conocer el absoluto, esto es una ruptura con la razón de la Aufklärung, ahora el sentimiento y la intuición estética serán los únicos capaces de conocer verdaderamente. Así, al entablar un diálogo álgido con la tercera crítica de Kant, los Romantiker proponen 
una filosofía de la naturaleza (Naturphilosophen), donde en la idea fuerza (Kraft) se encuentra el medio entre lo mental y lo físico, lo real y lo ideal, lo subjetivo y lo objetivo; la creatividad artística es el culmen de todas las fuerzas de la naturaleza.

En "El concepto de Bildung en el primer romanticismo alemán", Beiser nos aclara que la Bildung es para los Romantiker la aspiración más elevada de los hombres, ellos consideraban que la solución a los problemas de la sociedad estaba en la educación. De esta forma, la Bildung era considerada el único fundamento del Estado, en ella va la autorrealización del individuo. La Bildung garantiza que las personas sean buenos ciudadanos, así, debe ser misión del Estado arropar, promover y fomentar su actividad entre los hombres; la cual, desde la concepción romántica, consiste en una autorrealización estética, que tiene como finalidad la libertad del individuo.

En el siguiente capítulo, que lleva por título "Friedrich Schlegel: el misterioso romántico", se nos habla de que, para Schlegel, el romanticismo fue sumamente atractivo, pues no requería de un dogmatismo semejante al que profesaba la Aufklärung en la razón, mucho menos estipulaba una sistematización rígida como lo pretendía la filosofía kantiana o la hegeliana. Al contrario, lo que seducía al Schlegel a adentrarse en el pensamiento romántico era el anhelo de infinita contemplación artística en el cual los Romantiker habían fundamentado su propuesta filosófica. Beiser afirma que el arte que cubría a cabalidad la expectativa romántica de una experiencia estética total era la poesía, caracterizada por ser una mezcla de géneros artísticos, un esfuerzo eterno, un alejamiento del autocontrol, un enfoque irónico, un alejamiento de las preocupaciones al mismo tiempo que un acercamiento a la belleza pura y una relación entre el arte, la moral y la ciencia. Así pues, para Schlegel la poesía romántica es una representación total de su época y el arte que lleva a los hombres a una idea de totalidad universal.

Siguiendo su lectura romántica, Beiser, en un octavo capítulo nombrado "La paradoja de la metafísica romántica”, nos explica que los Romantiker hicieron un esfuerzo por proponer una metafísica que fusionara el idealismo de Fichte y el realismo de Spinoza. 
Ésta postula como categoría principal el concepto de naturaleza orgánica, mismo que evita distinciones de clase entre el ámbito mental y el físico; propone sólo una distinción entre los diferentes niveles en que se organiza la fuerza vital de la naturaleza. A partir de la naturaleza orgánica se puede pensar que todo lo existente en el mundo natural forma parte de un todo vivo, donde las partes no se pueden separar del todo, al mismo tiempo que el todo no puede ser separado de sus partes.

En el noveno apartado del libro, "Kant y los Naturphilosophen", el autor asegura que los Romantiker entablaron un diálogo crítico con la filosofía kantiana; señala que en el planteamiento filosófico de Kant no hay una clara distinción entre filosofía y ciencia; por lo cual los Romantiker proponen una Naturphilosophie capaz de generar una metafísica que, sin estructuras previas, a través de la poesía, capte y entienda la totalidad del mundo natural para expresarla con verdad por medio de categorías estéticas.

Por último, en el décimo capítulo denominado "Religión y política en la Frühromantik" el profesor Beiser refiere un estereotipo bastante común sobre el romanticismo que, a su juicio, resulta bastante conflictivo: afirma que los Romantiker proponen sólo un movimiento artístico que coloca al arte como un fin en sí mismo, lo cual obligaría a los filósofos románticos a limitarse al mundo imaginario de la literatura, renunciando a hacer una propuesta filosófica y política. Sin embargo, para el autor, lo anterior se encuentra muy lejos de ser cierto, pues para la Frühromantik la política es un aspecto integral de la propuesta, ya que para los Romantiker alcanzar el bien supremo es un objetivo prioritario, entendido como la autorrealización personal que lleva a los hombres a la excelencia humana, la cual sólo puede alcanzarse por medio de la Bildung. De esta forma los Romantiker priorizan la ética sobre la política, en espera de que la verdadera Bildung se realice por medio de la educación del Estado. Esto puede extrapolarse al ámbito religioso, nuestro autor afirma que la religión es un elemento de suma importancia en la idea de Bildung romántica. Los Romantiker esperaban que por medio de 
la educación y la Bildung se llegara a una vida política en la cual imperara un humanismo religioso.

En su obra El imperativo romántico Frederick Beiser presenta una lectura innovadora e interesante sobre el romanticismo, la cual, sin duda, salva a esta filosofía de los prejuicios surgidos de diferentes escuelas provenientes de la crítica de Hegel a estos autores, donde consideraban a los románticos, en el mejor de los casos, literatos o poetas no merecedores de grandes méritos. Nuestro autor coloca a los Romantiker en un estatus de filósofos, otorgado por una propuesta de suma complejidad teórica, donde a través del arte poético se entiende la totalidad de la realidad y se explican sus dimensiones metafísicas, epistemológicas, políticas, éticas e incluso religiosas. La propuesta de Beiser le otorga la categoría que, con justicia, merece el romanticismo en la historia de la filosofía; nos permite entender planteamientos teóricos, filosóficos y artísticos como: la Gesamtkunstwerk wagneriana, el psicoanálisis, la filosofía heideggeriana y la hermenéutica. 